\title{
Training Strategy and its Effect on Employees' Performance in Yemen Mobile Company
}

\author{
Ahmed Naji Shaddad, C. Samudhra Rajakumar
}

\begin{abstract}
The study aimed to explore the application of activities related to training and development in Yemen mobile company and its effectiveness in improving the employee's performance. A final of 200 questioners were received, representing about $50 \%$ of the study population. The study found a positive correlation between training strategy and the employees' level of performance. The employees' performance also showed significant improvement due to adopting modern technology and training strategy programs. The results also revealed a statistically significant correlation between the progress in the performance of the employees and the degree of training diversity programs introducing in the company. Furthermore, there was a substantial correlation between applying the strategically designed stage of the training process in this company and improving the performance level. However, the application of the training activities mentioned above was hindered or delayed by factors like the scarcity of qualified trainers, the natural of the company's organizational culture, and the rigidity in the applications that govern this company's training practices. The study showed an acceptable level in adopting and applying for this company's training and development programs. The company should direct some more effort and attention to improving the application of training and development programs based on clear training strategy and divers training programs that serve the company's overall development. These efforts should also seek to rise the methods and technology needed to improve the company's employees' performance.
\end{abstract}

Keywords: Development, Performance, Training, Telecommunication Company

\section{INTRODUCTION}

This scientific progress that the world is witnessing today requires organizations, whether global or local, to adopt modern management concepts in management if they want to achieve their goals efficiently and effectively. Among this current management, concepts are the unquestioning belief in the necessity of the existence and application of strategic planning in organizations and institutions to survive, continue and face the various changes and challenges in light of globalization. Yemeni organizations are part of the global environment affected and affected by it, and there are

Revised Manuscript Received on October 10, 2020.

* Correspondence Author

Ahmed Naji Shaddad*, PhD Scholar, Department Business

C. Samudhra Rajakumar, PhD Scholar, Department Business Administration, Faculty of Arts ,Annamalai University, Tamil Nadu, India

(c) The Authors. Published by Blue Eyes Intelligence Engineering and Sciences Publication (BEIESP). This is an open access article under the CC BY-NC-ND license (http://creativecommons.org/licenses/by-nc-nd/4.0/) Administration ,Faculty of Arts ,Annamalai University, Tamil Nadu, India

challenges and rapid changes that affect these organizations. This, therefore, requires Paying attention to and training human resources so that they have different knowledge and skills to face these rapid changes in all aspects of economic and technological life. The human resources strategies, including the training strategy, have an essential role in changing the practices related to the functions of human resources management. Thus, influence the performance of the organization in general, especially in the field of achieving competitive advantage so that the training strategy must operate in a broader framework that includes the strategy at the level of the organization as a whole which is from the initial conception of future visions of the organization and draw policy and determine the purpose of the long term and the statement of strengths and weaknesses to make decisions strategic right. Training has become, at present, an investment in human capital, as it is considered one of the most basic ways to create appropriate human resources in terms of quantity and quality as it works to provide individuals with the information and administrative and technical skills necessary to perform their work efficiently and effectively, and this thus reflects positively on the work and performance of organizations in general. The basic idea behind the comprehensive and integrated approach to strategically managing human resources is to coordinate all the organization's resources, including human resources, to ensure that it will lead to its primary strategy. Undoubtedly, integrating all the organization's resources will ultimately lead to the emergence of another added value. None of these resources can form alone, and this is one of the primary benefits resulting from the strategic management of a useful training function in the organization. The telecommunication sector has a key role in the development of Yemen's society and its development and growth of economic. This, therefore, requires the advancement of technology and the use of modern methods and sophisticated, making the need to have to involve the employees in this company training programs continued to face the changes ongoing in the light of globalization, through the application of our company's management strategy and improve its performance. For its various functions, continuous development of its operations, and attention to its human resources and training to achieve the goals, this study to find out the extent of Yemen Mobile's application of the training strategy and its impact on the performance of employees in this company.

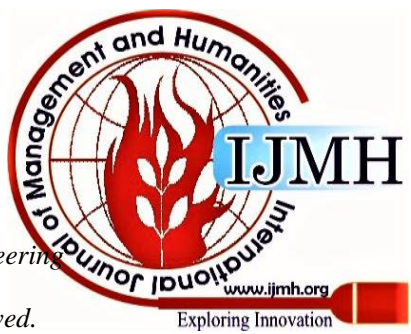




\section{A.Overview of Yemen Mobile Company}

Yemen Mobile Company is the first 3G Company in Yemen that provides CDMA20001x and EVDO services. Yemen mobile was established in 2004 as a third wireless operator in Yemen and initially offered the circuit switch services besides to packet switch services, which enable its customers to use data services and the internet at a speed of $153 \mathrm{kbps}$ as a maximum rate by implementing CDMA20001x, which is 2.5G technology according to 3GPP2 standard

\section{B. THE STUDY PROBLEM AND ITS QUESTIONS}

The lack of qualified, trained, and capable human resources to adapt to all variables and challenges in the external environment will lead to weak organizations' ability to compete globally and regionally. The training must be viewed from a strategic perspective so that training programs are designed and implemented to achieve the organization's strategic goals.

The problem of the study lies in trying to answer the following comprehensive question: "What is the extent of Yemen Mobile's implementation of activities related to the existence of a clear strategy for training and its impact on the level of performance of its employees?" Hence, this study attempts to reach the desired results by answering the following sub-questions:

1. Is there a relationship between the degree of implementation of Yemen Mobile Company, the stages of the training process from a strategic approach, and its employees' level of performance?

2. Is there a relationship between the quality of the training programs in Yemen Mobile and its employees' performance level?

3. Is there a relationship between the commitment of the top management and its adoption of the training strategy in Yemen Mobile and its employees' performance level?

4. Is there a relationship between the use of modern technology as a basis for implementing the training strategy in Yemen Mobile and the performance level of its employees?

\section{Importance of Studying}

The importance of this study stems from the fact that it focuses on a critical topic that affects the company's competitiveness and the achievement of its goals, especially telecommunications companies, which is the subject of training, as training is a long-term investment of the company's most important resources through the development and development of skills and knowledge of employees and thus leads to improving their performance, increasing productivity and achieving The organization aims to increase its competitiveness regionally and internationally. The importance of this study also stems from the fact that it focuses on the strategic dimension of the training function in Yemen Mobile and its impact on the performance of its employees, as many studies focused on the traditional measurement and did not focus on the strategic dimension of the training function. The importance of this study is evident in that it may contribute to assisting Yemeni companies in general by benefiting from its results and knowing what is applied to them and what needs to be involved, as adopting a training strategy is a significant step in defining the future vision of human resources management and thus contributes to improving the performance levels of employees and contributes to Achieve the competitive advantage of these organizations. The importance of this study also stems from the fact that it will contribute to providing interested and responsible people with the information they need and the most significant obstacles that prevent adopting the strategic approach in practicing training activities and finding appropriate mechanisms and solutions for the success of applying this approach to raise the level of performance of employees in these organizations.

\section{Objectives of the Study}

This study sought to achieve the following objectives:

1. Demonstrate the degree of Yemen Mobile application stages of the training process from a strategic approach.

2. Demonstrate the application of Yemen Mobile's practice of building training strategy steps.

3. Identify the most prominent types of training programs that are offered to employees in Yemen Mobile

4. Knowing the extent of the senior management's commitment, adoption, and support to Yemen Mobile's training strategy.

5. A statement of the extent to which Yemen Mobile has adopted modern technology as a basis for implementing training strategy programs.

6. Identify the most significant obstacles that Yemen Mobile faces when adopting an effective training strategy.

\section{E. The limitations of the stud}

- Spatial and procedural boundaries determined this study. In terms of place, this study will be limited to Yemen Mobile.

- In terms of the procedure, this study will be applied to the study sample of the Yemen Mobile Company employees.

\section{F. Terminology of Study}

Training: It is the planned process to change behavioral trends and provide them with knowledge and skills through educational experience to achieve effective performance in a specific activity or field, develop employee capabilities, and achieve the organization's current and future workforce needs.

Training programs are a group of organized, planned, and continuous activities aimed at providing trainees in the organization with specific knowledge, improving and developing their skills and capabilities, and changing their behaviors positively and constructively.

Training strategy: a set of activities aimed at designing and implementing a set of practices and policies related to training homogeneous human resources internally in how human capital is achieved that contributes to achieving the organization's strategic goals.

Types of training programs: These are internal training programs (to be held inside the company's training centers), and external training programs (to be held outside the company's training centers). These programs include lectures, discussions, conferences and seminars, case study methods, role representation, committees, and the method of rotating work and individual tasks.

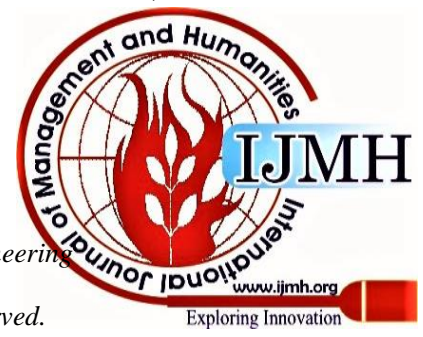


Training process: It is the process that includes the following stages: identifying training needs, planning, and organizing the training program, implementing the training program, and evaluating the training program.

\section{REVIEW OF RELATED LITERATURE}

The researcher tried to obtain previous studies on the study's subject and list the most relevant studies, which are as follows.

A study on training factors and its impact on training effectiveness in Kedah state development corporation Kedah Malaysia by Sanjeevkumar (2011) was aimed to combine theoretical and experimental research in trying to find the factors that effects on staff training and its impact on the practice of human resources, results showed a relationship between training, job environment and individual staff characteristics. It shows that the training environment has a strong effect on the training process. It suggests affording more time and resources in this area as it brings excellent effectiveness to a company.

Abdelgadir and Elbadri (2001) studied the identification of training needs, developed training programs, and evaluated the effectiveness. The study found that many of these banks ignore the process of identifying training needs, the absence of assessing the results of training programs, and the consequence of this on individuals' performance.

Teresa Brannick et al. (2002) aimed to know the impact of training practices on the level of service provision. The researchers collected data from (143) service companies in Ireland. The study concluded that providing intensive and properly planned training programs significantly contributes to improving individuals' ability to provide services with a high level of skill, thus increasing customer satisfaction.

Daniels (2003) found out that the training process returns on individuals working in (15) British banks. The study concluded that training contributes significantly to developing working individuals' skills and learning, building effective work teams, achieving high-quality levels, and creating an organizational culture that supports the organization's goals and strategies. This, in turn, contributes to achieving a good return on investment in training.

Gasc ó et al. (2004) study focused on knowing how to use information technology on human resource management practices, especially the Spanish telecommunications company (Telefonica). The most important findings of this study were using information technology in training. It has contributed significantly to improving managers' exploitation for their time, increasing participation thousand high of trainees, and improving the evaluation of the effectiveness of systems training programs, improving after the quality and quality of these programs. This service company aims to develop its future training systems to become based on self-learning e-learning for employees. The most important thing that distinguishes this study from previous studies is that it is:

1. It tries to approach the training activity from a strategic perspective to consider the need for an integration between the organization's general strategy and the human resource strategy to achieve the organization's strategic objectives, as most of the previous studies, especially the Arab ones. It dealt with training from a traditional rather than a strategic perspective, as this study focuses on the strategic dimension of the training function. Thus, it is trying to determine the extent to which Yemen Mobile is pursuing strategic planning and the existence of a clear strategy for the organization that includes a set of functional strategies, including the human resources strategy, from which the training strategy stems.

2. This study focuses on trying to identify how to choose the training programs in Yemen Mobile. This process is done in a scientific and studied manner according to the internal and external environment data or in an unexpected traditional way. The training needs are taken into account when determining the company's general strategy. It is done in a pattern. Is it random to refer to the performance reports of the company's employees when determining training needs? This study is considered one of the rare studies applied to the training strategy and its impact on the performance of Yemen Mobile employees.

Concept of Training:

A lot of researchers and writers in the field of management define training from different angles. However, all agreed eventually to its role in raising the working efficiency of the organization as a whole, where Khaled Hiti (2004) believes that training is "work or activity of human resources management activities, which works on the report of the need of individuals employees at various organizational levels for the development and rehabilitation, in the light of the strengths and weaknesses in their performance and their behavior during work."

Salah Abdul Bakr (2004) defined training as "planned activity designed to provide individuals with a range of information and skills that lead to increased individual performance rates at work."

Omar Aghili (1996) believes that training is " a planned process that is using the methods and tools to create, improve and refine the skills and abilities of the individual, and to expand his knowledge of the efficient performance through learning to raise the level of efficiency and thus established the efficiency in which it operates as a group of work '.

Hence, it can be said that the majority of researchers and writers have participated in defining training in common matters, the most important of which is that it provides individuals with specific skills that lead to an increase in individuals' performance rates and that it is an activity aimed at improving and developing work methods within the organization.

The researcher considers the necessity and importance of linking learning with training, as learning is viewed as a means of training. Without it, the training process cannot occur, as learning is concerned with providing individuals with scientific knowledge and connecting them to sound thinking. As for training, it is concerned with transferring knowledge to an actual application, as training is the core of learning.

From the previous definitions of training, the researcher concludes that training is a continuous process aimed at:

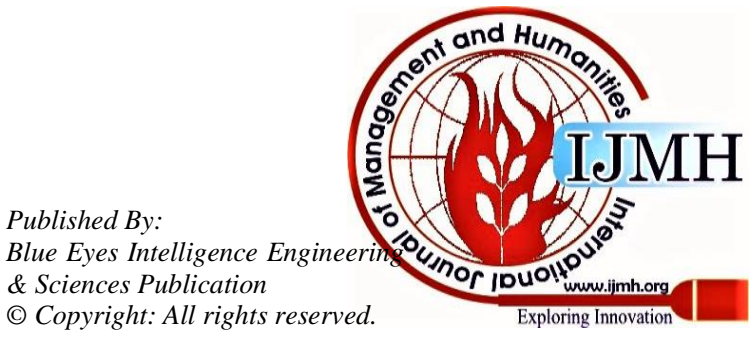




\section{Training Strategy and its Effect on Employees' Performance in Yemen Mobile Company}

- Providing and imparting the individual to skills, information, and experiences that he does not have or lacking and thus improving his performance and improving the organization's performance.

- Provide the individual with new trends and behavioral patterns.

- Providing, improving, and refining the skills of the individual.

\section{METHODS OF THE STUDY}

\section{A.Study Design}

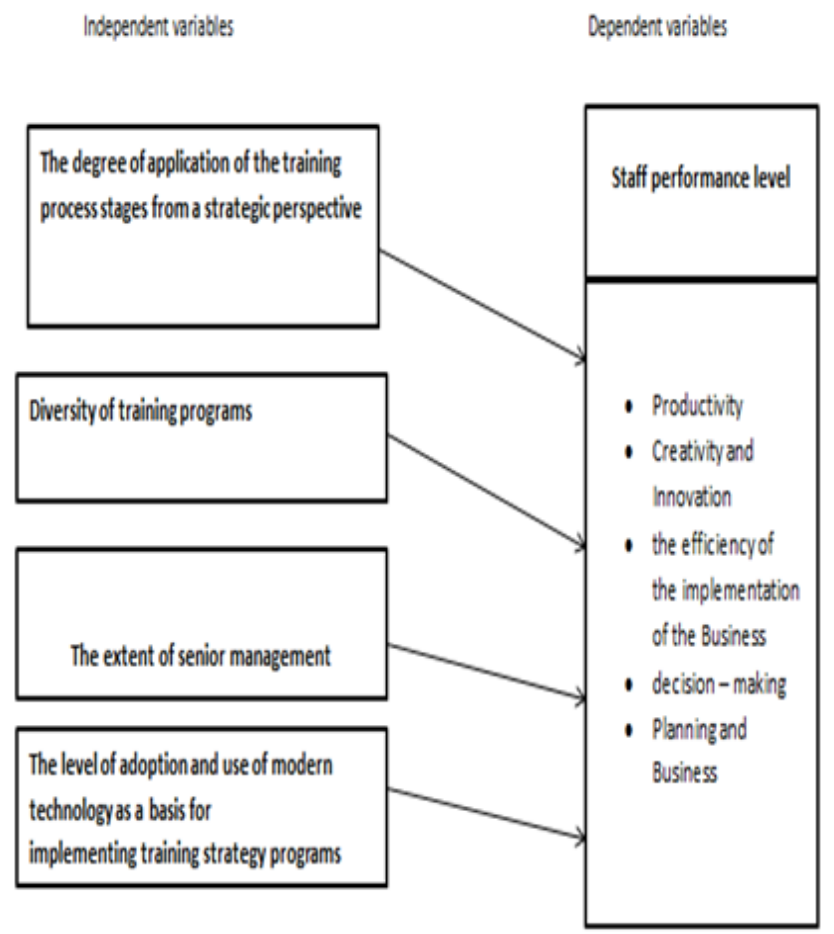

\section{B. Study Hypotheses}

The study hypotheses are based on the study problem and its various elements to achieve the desired study objectives, namely:

The first null hypothesis: There is no significant relationship between the degree of application of the training process stages from a strategic perspective and employee performance in Yemen Mobile Company.

The second null hypothesis: There is no significant relationship between the degree of application of the quality of training programs and employee performance in Yemen Mobile Company.

The third null hypothesis: There is no significant relationship between the commitment of senior management and the adoption of a training strategy in the company Yemen Mobile and the staff level's performance.

Fourth null hypothesis: There is no significant relationship between the use of modern technology as a basis for applying training programs strategy in Yemen Mobile Company and the level of performance of employees.

\section{Population and Sample Study}

The study population consisted of employees of the Yemen Mobile Company. A random sample of (50\%) was selected from the study population for the study sample.

\section{Data Collection Methods}

The researcher relied on the following sources for data collection, which requested this study are as follows:

\section{Primary Data:}

1. Questionnaire: A questionnaire was developed and distributed to Yemen Mobile Company to collect the necessary data for this study. (300) questionnaires were distributed (200) questionnaires were retrieved from this company 20 questionnaires were excluded because they were not valid and clear, and there remain two hundred questionnaires on which the study was conducted. Likert scale was used to measure these axes as follows: (1) for a shallow degree, (2) for a low degree, (3) for a medium degree, (4) for a high degree, and (5) for a very high degree. 2. Personal interviews: The researcher conducted some interviews to inquire and obtain some information that he needs in this study.

Secondary Data:

These data are represented in books and periodicals related to the topic and the various articles available on the global information network on the Internet. The various publications issued by the company and the Yemeni Ministry of Communications were used.

\section{E. Validate the Study Tool}

To ensure the clarity of the questionnaire and its suitability to measure the study's hypotheses, the researcher presented it to five faculty arbitrators, and all observations and opinions expressed by the referees were taken into consideration. Then the final version of the questionnaire was prepared.

\section{F. Stability Test Of The Study Tool}

Cronbach alpha coefficient was used (Cronbach Alpha) To measure the study sample's degree of reliability to the questionnaire questions. This parameter depends on measuring the questionnaire questions' internal reliability in their ability to give consistent results to the respondents responses towards the questionnaire questions, and alpha can be interpreted as the internal stability factor (Internal Consistency) Among the answers. Therefore, its value ranges between $(0,1)$, and that the statistically acceptable amount of the alpha coefficient is (60\%) or more so that the reliability of the scale is good and so that the results can be generalized as the value of alpha is (93.7\%).

\section{G. Methods of Data Analysis}

The statistical methods were chosen according to the study's nature by using the statistical program Statistical Package for Social Sciences (SPSS). In analyzing the data collected for the study, descriptive statistical methods such as percentages, frequencies, mean and standard deviation were used to give a comprehensive description of the sample members' responses to the various paragraphs of the questionnaire.

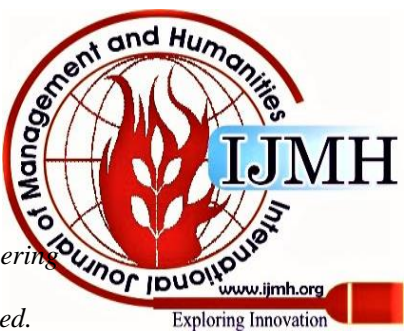




\section{H. The Theoretical Framework of The Study}

The basis of the training process is the delivery of information and the formation of specific skills to a group of trainees by means of communication and training methods, to influence their behavior and raise their job capabilities, and the training also aims to provide the individual with knowledge, skill, and behavior directly related to his career role, which increases his level of productivity at work.

Training has become a significant issue for many organizations in all sectors due to changing performance standards in these organizations, which are no longer limited to merely providing a service or product, but rather by ensuring the provision of quality that meets the customer's need and desires. Therefore, training has become of great importance and the focus of many researchers and specialists in the field of modern management.

\section{RESULTS DISCUSSIONS AND HYPOTHESES TESTING}

Table 1: General Characteristics of the Study Sample

\begin{tabular}{|l|l|l|}
\hline Characteristic & Number & \% \\
\hline Gender & 180 & 90 \\
Male & 20 & 10 \\
Female & & \\
\hline Age (years) & 40 & 20 \\
$<\mathbf{3 0}$ & 60 & 30 \\
$\mathbf{3 0}$ to 40 & 70 & 35 \\
$\mathbf{4 0}$ t0 50 & 30 & 15 \\
$\mathbf{5 0}$ to 60 & & \\
\hline Qualification & 0 & 0 \\
High school & 0 & 0 \\
Diploma & 150 & 75 \\
Bachelor & 50 & 25 \\
Master & 0 & 0 \\
PhD & & \\
\hline Experience (years) & 25 & 12.5 \\
3> & 30 & 15 \\
$\mathbf{5 - 3}$ & 35 & 17.5 \\
$\mathbf{1 0 - 5}$ & 110 & 55 \\
$\mathbf{1 0}>$ &
\end{tabular}

Gender: It was found that most of the study sample was male, as their number reached (80) persons with a percentage of (90\%), while the number of females was (20) females with a rate of $(10 \%)$, and this indicates the low percentage of female participation, in Yemen mobile company.

Age: It was found that the largest percentage of the study sample individuals are in the age group between 40 to less than 50 years, as their number reached (70) with a rate of (3 5 $\%)$, followed by the age group from 30 to less than 40 years. With a percentage of (30\%), the rate of those in the ages from 50 to less than 60 years was $20 \%$ of the total study sample, while the lowest percentage was for those with periods less than 30 years, their number reached ( 30 ) individuals and a rate of ( $15 \%$ ) from The overall study sample. This indicates that the average age of the study sample individuals is relatively high.
Academic Qualification: It was found that the majority of the study sample hold a first university degree (BA), as their number reached (150), and with a representation rate of (\%75), followed by the proportion of holders of a master's degree by (\%25) and this, therefore, shows that the individuals in the study sample are Those with relatively high academic qualifications.

Years of Experience: It was found that the relative distribution of the study sample is according to the number of years of experience, as the largest percentage was for those with experience of 10 years or more, the number of its members amounted to ( 110 ) and by ( $55 \%$ ), followed by the number of years of experience of 5-9 years and above amounted percentage (\%17.5), the owners of the knowledge of 3- 5 years has accounted for ( $15 \%$ ) of the total study sample,

The lowest representation was experienced less than three years have numbered (25) members and reached the proportion of representation (\%12.5) of the total study sample. This shows that the individual's enjoyment of the study sample experienced a long process.

\section{A. Discussions Of The Study Questions}

This study posed several questions directly related to the training strategy's placement, as it will attempt to answer the questions based on the data collected and analyzed.

It was found that the paragraphs of the questionnaire (1-14) are of a high degree of importance, as their average was more elevated than (3.00), meaning that there is agreement on all the questionnaire questions for the first variable related to the degree of the company's application of the training process stages from a strategic perspective.

It was found that the paragraphs of the questionnaire (15-20) were of low importance, except for sections (15 and 17 ), as they were of high priority, and it was found that the most used methods in training programs in this company are those programs that are based on the technique of lectures.

It was also found that the paragraphs of the questionnaire for questions (21-25) were of a relatively high level of importance, which indicates that the senior management in the company adopts a training strategy. The study results showed that the senior management seeks continuous improvement in work and finds ways and methods of work that Lead to better business execution.

It turned out that the study sample answers to questions from (29-26) were directed towards that modern technological means help in better delivery of the training material, as the study sample company use traditional standards such as blackboard and slide show machines in their training operations.

It was found through the questionnaire questions from (30-39) that the most crucial obstacle facing the process of adopting an effective training strategy is the lack of an organizational culture that supports the company's training strategy. The second obstacle in the degree of importance is the lack of highly qualified trainers in the company. The third obstacle was the rigidity of laws and regulations for training in the researched company.

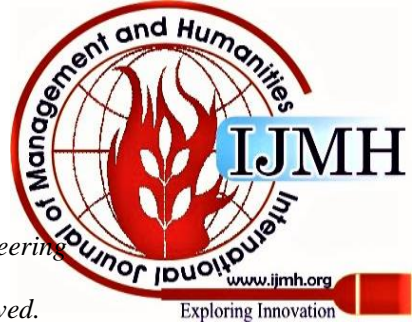


It emerged from the questionnaire questions (40-55), which shows the extent of the existence of a clear strategy for training and their contribution to improving the performance of individuals working areas, where the strategy shows the presence significantly in the trap of the study sample, which indicates that the company is applying it to a high degree.

\section{B. Testing the Hypotheses of The Study}

The first null hypothesis:

There is no Statistically significant relationship at the level of $\geq 0.05$ between the degree of application of the stages of the training process from a strategic perspective and employee performance in Yemen Mobile Company. to examine whether there were significant differences between the averages of the study sample's estimates of the relationship between Yemen Mobile's application of the stages of the training process from a strategic perspective and the level of employees ' performance, at the level of statistical significance $\cdot(0.05=$. Table 2 shows the results related to analyzing this relationship.

Table 2: Regression test results and $F$ test Results

\begin{tabular}{|c|l|c|l|c|}
\hline $\mathbf{R}$ & $\begin{array}{c}\text { Adjusted } \\
\mathbf{R}^{\mathbf{2}}\end{array}$ & $\mathbf{F}$ & $\begin{array}{c}\text { Level of } \\
\text { significance }\end{array}$ & Result \\
\hline 0.673 & 0.449 & 161.853 & 0.000 & rejected \\
\hline
\end{tabular}

The results show that $\mathrm{F}=161.853$ with a level of significance of 0.000 , which is less than the specified value (0.05), indicating the existence of statistically significant differences between the application of Yemen Mobile Company of the stages of the training process from the perspective of training strategy and the level of staff performance. This result was supported by Adjusted $\mathrm{R}^{2}$, which amounted to (0.449).

The second null hypothesis:

There is no Statistically significant relationship at the level of $\geq 0.05$ between the degree of application of the quality of training programs and employee performance in Yemen Mobile Company.

The study tried to identify whether there were significant differences between the averages of the study sample's estimates of the relationship between the quality of training programs in Yemen Mobile and the level of employee performance, at the level of statistical significance • (0.05 $=$ Table 3 shows the results related to analyzing this relationship.

Table 3: Regression test results and $F$ test Results

\begin{tabular}{|c|c|c|c|c|}
\hline $\mathbf{R}$ & $\begin{array}{c}\text { Adjusted } \\
\mathbf{R}^{2}\end{array}$ & $\mathbf{F}$ & $\begin{array}{c}\text { Level of } \\
\text { significance }\end{array}$ & Result \\
\hline 0.324 & 0.101 & 23.575 & 0.000 & rejected \\
\hline
\end{tabular}

The results show that $\mathrm{F}=23.575$ with a level of significance of $p=0.000$, which is less than the specified value $(0.05)$, indicating statistically significant differences between the quality of training programs in the company Yemen Mobile And the level of performance of employees. Therefore, the null hypothesis was rejected.

The third null hypothesis:
To test the hypothesis, a regression test and $\mathrm{F}$ test were used

There is no Statistically significant relationship at the level of $\mathrm{p} \geq 0.05$ between the adoption of senior management training strategy and the level of employee performance in Yemen Mobile Company.

To test the hypothesis, a regression test and $\mathrm{F}$ test were used to find out whether there were significant differences between the averages of the study sample's estimates of the relationship between the adoption of the senior management in Yemen Mobile Company for the training strategy and the level of employee performance, at the level of statistical significance $(0.05)$ Table 4 shows the results related to analyzing this relationship.

Table 4 Regression test results and F test Results

\begin{tabular}{|c|l|c|l|l|}
\hline $\mathbf{R}$ & $\begin{array}{c}\text { Adjusted } \\
\mathbf{R}^{2}\end{array}$ & $\mathbf{F}$ & $\begin{array}{c}\text { Level of } \\
\text { significance }\end{array}$ & Result \\
\hline 0.513 & 0.267 & 71.759 & 0.000 & rejected \\
\hline
\end{tabular}

The results show that $\mathrm{F}=71.759$ with a level of significance of $p=0.000$, which is less than the specified value (0.05), indicating statistically significant differences between the adoption of senior management training strategy and the level of performance of employees in Yemen Mobile Company. Therefore, the null hypothesis was rejected.

The fourth null hypothesis:

There is no statistically significant relationship at the level of significance $\geq 0.05$ between the use of modern technology as a basis for applying training programs strategy in Yemen Mobile Company and the level of performance of employees.

Table 5: Regression test results and test $F$ Resulting from

\begin{tabular}{|c|c|c|c|c|}
\hline $\mathbf{R}$ & $\begin{array}{c}\text { Adjuste } \\
\mathbf{d ~ R}^{2}\end{array}$ & $\mathbf{F}$ & $\begin{array}{c}\text { Level of } \\
\text { significance }\end{array}$ & Result \\
\hline 0.478 & 0.237 & 61.391 & 0.000 & rejected \\
\hline
\end{tabular}

The results show that $\mathrm{F}=61.391$ with a level of significance of $\mathrm{p}=0.000$, which is less than the specified value, $(0.05)$ indicating the existence of statistically significant differences between the use of modern technology as a basis for the application of training programs strategy in Yemen Mobile Company and the level of performance of employees. Therefore, the null hypothesis was rejected.

\section{GENERAL DISCUSSION}

The study reached the following results:

1. The low rate of female participation in the Yemen Mobile Company, as the percentage of males who were included in this study is $90 \%$, and this thus indicates that there are social obstacles related to customs and traditions that women working in Yemeni companies face that prevent them from joining these company.

2. The majority of the sample members in the company are highly educated, as the number of holders of a bachelor's degree reached $\%$ 75and holders of a master's degree \% $25 \mathrm{Of}$ them are over 40 years old, and most of them have more than ten years of experience.

Published By:

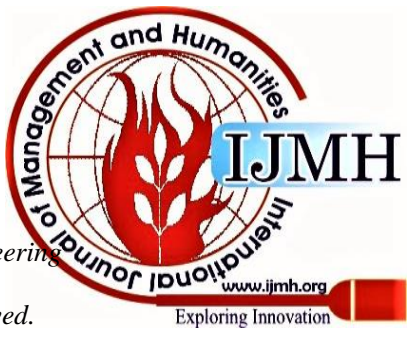


3. The degree of Yemen Mobile's application of all activities related to the training process phases from a strategic perspective represented by identifying training needs, designing training programs, implementing training programs, and evaluating and evaluating training programs) was high. Therefore, this indicates that the interest of this company has a clear training strategy.

4. That Yemen Mobile Company focuses on lectures to a considerable extent in the training process and focuses on job rotation techniques. In contrast, other forms of training are weak or almost non-existent.

5. The senior management in Yemen Mobile Company seeks primarily to continuously improve work and find ways and work methods that lead to better implementation of the work. Its interest in providing the necessary material capabilities and continuously following up on the training process and considering training among its strategic priorities came to a relatively lesser degree.

6. That Yemen Mobile Company uses modern technological means to implement training strategy programs at a weak degree, which consequently negatively affects employees, given that modern technical means help deliver the training material better. At the same time, this company focus on using traditional means to implement their training strategies to a high degree.

7. This study revealed a set of obstacles that this company faces in the process of adopting an effective training strategy, the most prominent of which is the lack of an organizational culture supportive of the training strategy in this company, the lack of highly qualified trainers, and the rigidity of laws and regulations for training in this company.

8. The level of the training strategy's contribution to improving individuals working in Yemen Mobile from managers and in related fields was to a high degree. The best way in the field of (decision-making (the ability to analyze facts and reach logical results and business planning and implementation ability Emphasis on getting the work done and the ability to choose the right and appropriate actions to carry out the work.

9. The existence of a positive correlation relationship with statistical significance between Yemen Mobile's application of the stages of the training process from a strategic perspective and the level of performance of its employees, as well as the existence of this relationship between the degree of diversity of the training programs provided in this company and the performance of its employees.

10.The existence of a positive correlation with statistical significance between the extent of the senior management in this company adopting the training strategy and the level of employee performance, as well as the existence of this positive relationship between the use of modern technology as a basis for implementing the training strategy programs in this company and the performance level of its employees.

\section{RECOMMENDATIONS}

The study reached several recommendations:

1. The necessity for the Yemen Mobile Company to provide more attention and support by senior management to adopt clear training strategies emanating from the company's general strategy.
2. The necessity for the Yemen Mobile Company to diversify the training methods that it provides to its employees, as it focuses on the method of lectures and job rotation to no small degree. Therefore, discussion methods, case studies, committees, and conferences must be added to these methods because of their impact on improving employees' performance levels in This company.

3. The need to pay attention to providing the financial and material capabilities necessary for the training process and the necessity to consider training among the company's strategic priorities.

4. Yemen Mobile Company has to adopt modern technological means to implement training strategy programs because of its positive impact on the training process, which thus affects improving the performance level of the employees of this company.

5. Yemen Mobile Company must reduce the obstacles and obstacles it faces when adopting an effective training strategy by spreading the organizational culture that supports the training strategy, providing highly qualified trainers, and changing its regulations and laws that contradict the adoption of a clear and effective training strategy.

6. Take advantage of the high academic qualifications and long practical experience of the managers in this company by following the sound strategic planning and a clear strategy for the company from which a clear strategy for the various functional units emerges.

7. The necessity to base the training activity in Yemen Mobile on the strategic approach, which requires considering all factors in the internal and external environment and responding to these variables, and building this activity in an integrated and comprehensive manner in light of the surrounding environment data.

\section{REFERENCES}

1. Abdelgadir, N., and Elbadri A. (2001). Training Practices of Polish Banks: An Appraisal and Agenda for Improvement. Journal of European Industrial Training, Vol. 25, Issue 2, pp. 69-79.

2. Assaf, A. (2000). Training and Human Resource Development: Foundations and Operations, Amman: Zahran House

3. Al- Hiti, K. (2004). Human Resources Management: A Strategic Introduction, Amman: Wael Publishing House

4. Al-Salem, M and Saleh A. (2002). Human Resources Management: A Strategic Approach, Irbid: Modern Book World for Publishing and Distribution

5. Aqili, O. (1996). Manpower Management, Amma n: Zahran Publishing House

6. Abdel- Baqi S. (2000). Human Resources Management from a Scientific and Practical point of view, Cairo: University House.

7. Appleby, A, and Marvin, S. (2000). Innovation Not Limitation: Human Resource Strategy \& the Impact on World Class Status. Total Quality Management, Vol. 11, No. 415, pp. 554-561.

8. Brannick T, de Burca S., Fynes B, Roche E., Ennis S. (2002). Service Management Practice-Performance Model: A Focus on Training Practices, Journal of European Industrial Training, Vol. 26, Issue 8, pp. 394-403.

9. Jos é L. G, González LJ, and Reyes M. (2004). "The Use of Information Technology in Training Human Resources: An E-learning Case Study." Journal of European Industrial Training, Vol. 28, Issue 5, pp. 370-382.

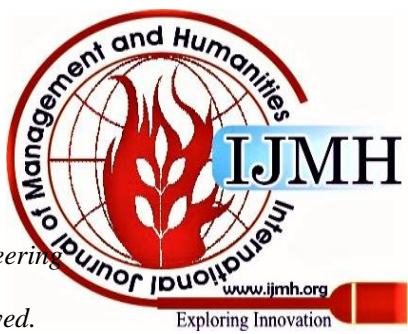


10. Leonard D. and McAdam, R. (2001). The Strategic Impact and Application of the Business Excellence Model: Implications for Quality Training and Development. Journal of European Industrial Training, Vol. 26, Issue 1, pp. 4-13.

11. Sharon D. (2003). Employee Training: A Strategic Approach to Better Return on Investment. Journal of Business Strategy, Vol. 24, Issue 5 , pp. 39-42.

12. Sanjeevkumar V and Yanan H. (2011) A study on factor and its impact on training effectiveness in Kedah state development corporation Kedah Malaysia international journal of human resource studies 1 (2.136)

13. Zdunczyk, K., and Blenkinsopp, J. (2007). Do Organizational Factors Support Creativity and Innovation in Polish Firms? European Journal of Innovation Management, Vol. 10, Issue 1, pp. 25-40.

\section{AUTHORS PROFILES:}

Ahmed Naji Shaddad, Ph.D. Scholar, Department Business Administration, Faculty of Arts, Annamalai University, Tamil Nadu, India.

Dr. C. Samudhra Rajakumar, Professor, Department Business Administration, Faculty of Arts, Annamalai University, Tamil Nadu, India. Thirty-one years of academic experience, and 8 International Publications. 